\title{
Lipid profile among controlled and uncontrolled type-2 diabetic patients in a rural tertiary care center: a comparative study
}

\author{
Manu Gangadhar ${ }^{1}$, Narasimhamurthy K. Muthahanumaiah ${ }^{2 *}$
}

\author{
${ }^{1}$ Department of Pharmacology, Adichunchanagiri Institute of Medical Sciences, B. G. Nagar, Nagamangala Taluk, \\ Mandya Pradesh, Karnataka, India \\ ${ }^{2}$ Department of Pharmacology, Basaveshwara Medical College and hospital, Chitradurga, Karnataka, India
}

Received: 30 December 2019

Revised: 12 February 2020

Accepted: 15 February 2020

\section{*Correspondence:}

Dr. Narasimhamurthy K. Muthahanumaiah,

Email:drmanugigu@gmail.com

Copyright: (C) the author(s), publisher and licensee Medip Academy. This is an open-access article distributed under the terms of the Creative Commons Attribution Non-Commercial License, which permits unrestricted non-commercial use, distribution, and reproduction in any medium, provided the original work is properly cited.

\begin{abstract}
Background: Diabetes mellitus is one of the major health problem and endemic with rapidly increasing prevalence in both developed and developing countries. It has strong association with dyslipidaemias in relation to glycaemic control and duration of the disease. Dyslipidaemias make diabetic patients more susceptible to coronary artery disease (CAD) which is the major cause of increased mortality and morbidity. Objectives were to estimate the blood glucose levels and lipid profiles among diabetics and to compare the lipid profiles among controlled and uncontrolled diabetic subjects.

Methods: A cross sectional study was done including 100 diabetic subjects aged between 40 to 60 years of either sex. Patients were classified into 2 groups with 50 subjects in each group as per their glycemic index. Group 1 was controlled diabetic patients (HbAlc $\leq 7.5 \%)$ and Group 2 was uncontrolled diabetic patients (HbA1c>7.5\%). Venous blood samples were collected from the subjects. The serum was used for analyzing FBS, PPBS, HbA1c and lipid profiles.

Results: FBS, PPBS, HbA1c, total cholesterol, triglycerides and LDL were more in females than male patients but the mean values were not significant statistically except FBS and total cholesterol. All the lipid parameters were elevated among uncontrolled diabetic patients compared to controlled diabetic patients which was statistically significant.

Conclusions: Present study concluded that the blood glucose levels and lipid parameters were elevated among uncontrolled diabetics compared to controlled diabetics strongly depicting the co-relation between the glycemic levels and lipid abnormalities. Patients should be educated to monitor regularly and control blood glucose and lipid levels.
\end{abstract}

Keywords: Blood glucose levels, Diabetes mellitus, Glycated haemoglobin, Lipid profiles

\section{INTRODUCTION}

The term diabetes mellitus (DM) describes a metabolic disorder with different causative factors, which is characterized by chronic hyperglycemia and disturbances of carbohydrate, protein and fat metabolisms resulting from defects in insulin secretion, insulin action or both. ${ }^{1}$ Globally diabetes mellitus became one of the major health problems and endemic with rapidly increasing prevalence in both developed and developing countries. ${ }^{2}$

India, which is an emerging Asian country with rapid industrialization and a modern lifestyle, is experiencing a serious issue in holding the largest number of people with diabetes., The WHO has stated India as "Diabetic Capital" of the world. ${ }^{5}$ 
The long-term complication of diabetes mellitus includes dysfunction, damage to various organs, especially the heart, kidneys, eyes, nerves and blood vessels and are responsible for the majority of morbidity and mortality associated with the disease. ${ }^{6} \mathrm{DM}$ has strong association with dyslipidaemias in relation to glycaemic control and duration of the disease. ${ }^{7}$ Dyslipidaemias make diabetic patients more susceptible to coronary artery disease (CAD) which is the major cause of increased mortality and morbidity in these. ${ }^{8}$

Abnormal serum lipids are likely to contribute to the risk of coronary artery disease in diabetic patients and the determination of the serum lipid levels in people with diabetes is now considered as a standard of the diabetes care. $^{9,10}$

For long term glycemic control glycated haemoglobin (HbA1c) is used as a marker routinely. For both glycemic control and cardiovascular disease (CVD) risks HbA1c is use as the marker. ${ }^{11}$ For every $1 \%$ rise in $\mathrm{HbA} 1 \mathrm{c}$ value the estimated risk of CVD is $18 \%$ in diabetic patients. ${ }^{12}$

Impaired insulin action and relative insulin deficiency causes complex alterations in plasma lipids resulting in raised plasma very low density lipoprotein (VLDL) levels and decreased serum HDL-cholesterol level both causing increased rate of atherosclerosis and hence contributing to Coronary artery disease. ${ }^{13}$

Henceforth we aimed to estimate Fasting Blood Glucose, Postprandial Blood Glucose, HbA1c and lipid profiles among diabetic subjects and to compare the lipid profiles between controlled ( $\mathrm{HbA} 1 \mathrm{c} \leq 7.5 \%)$, and uncontrolled diabetic subjects (HbA1c>7.5\%).

\section{METHODS}

As per WHO diagnostic criteria for type-2 DM, a cross sectional study was done including 100 subjects aged between 40 to 60 years of either sex. The study was done in Adichunchanagiri Institute of Medical Sciences, for duration of 4 months from January 2017 to April 2017 after obtaining permission from the Institutional Ethical Committee.

Diabetic patients were classified into 2 groups with 50 subjects in each group as per their glycemic index. Group 1 was controlled diabetic patients $(\mathrm{HbA} 1 \mathrm{c} \leq 7.5 \%)$ and Group 2 was uncontrolled diabetic patients (HbA1c>7.5\%).

Patients who already had history of cerebrovascular disease, who were already on lipid lowering drugs, with other chronic metabolic disorders or systemic illness and with history of smoking and alcoholism were excluded from the study.

After obtaining the informed consent, venous blood samples were collected from all the subjects after at least 8 hours fasting. The serum was later used for analysing fasting blood sugar (FBS), HbA1c, lipid profile- serum total cholesterol (TC), triglycerides (TG), HDLcholesterol, LDL-cholesterol, VLDL-cholesterol and post prandial blood sugar (PPBS) after two hours of having breakfast.

All the parameters were assessed in both the groups and were compared. All values were expressed as mean \pm standard deviation of the mean. $\mathrm{P}$ value $<0.05$ was considered as significant.

\section{RESULTS}

Gender wise comparison of blood glucose and lipid profiles is presented in Table 1.

Table 1: Gender wise comparison of blood glucose and lipid profiles.

\begin{tabular}{|ll|ll|}
\hline Age & Male & Female & P value \\
\hline FBS & $50.08 \pm 0.86$ & $51 \pm 1.20$ & 0.526 \\
\hline PPBS & $139.55 \pm 6.37$ & $167.83 \pm 5.69$ & $0.0016^{*}$ \\
\hline HbA1c & $201.8 \pm 5.99$ & $207.5 \pm 5.72$ & 0.5066 \\
\hline $\begin{array}{l}\text { Total } \\
\text { cholesterol }\end{array}$ & $206.75 \pm 4.07$ & $220.95 \pm 5.03$ & $0.0305^{*}$ \\
\hline Triglycerides & $203 \pm 6.50$ & $217.35 \pm 9.90$ & 0.2090 \\
\hline HDL & $42.67 \pm 1.24$ & $40.01 \pm 1.09$ & 0.1173 \\
\hline LDL & $112.91 \pm 3.03$ & $113.42 \pm 4.33$ & 0.9210 \\
\hline VLDL & $45.95 \pm 1.45$ & $44.65 \pm 1.32$ & 0.5343 \\
\hline *represents significance. & & \\
\hline
\end{tabular}

Table 2: Comparison of lipid profiles among controlled and uncontrolled diabetes patients.

\begin{tabular}{|lllll|}
\hline Parameter & Group 1 & Group 2 & P value & F ratio value \\
\hline FBS & $139.78 \pm 6.84$ & $173.26 \pm 4.73$ & $0.000112^{*}$ & 16.02 \\
\hline PPBS & $185.92 \pm 4.49$ & $224.52 \pm 5.92$ & $0.00001^{*}$ & 26.92 \\
\hline HbA1c & $7.13 \pm 0.042$ & $8.55 \pm 0.123$ & $0.00001^{*}$ & 119.22 \\
\hline Total cholesterol & $198.18 \pm 3.75$ & $226.68 \pm 4.48$ & $0.00001^{*}$ & 23.97 \\
\hline Triglycerides & $174.38 \pm 3.41$ & $243.12 \pm 8.11$ & $0.00001^{*}$ & 61.00 \\
\hline HDL & $42.76 \pm 0.989$ & $39.4 \pm 1.30$ & $0.04268^{*}$ & 4.21 \\
\hline LDL & $93.7 \pm 1.693$ & $132.54 \pm 2.64$ & $0.00001^{*}$ & 152.56 \\
\hline VLDL & $39.06 \pm 0.914$ & $51.8 \pm 1.303$ & $0.00001^{*}$ & 64.02 \\
\hline
\end{tabular}

*represents significance. 
FBS, PPBS, HbA1c, total cholesterol, triglycerides and LDL were more in females than male patients but the mean values were not significant statistically.

Comparison of lipid profiles among controlled and uncontrolled diabetes patients is shown in Table 2. The lipid parameters were deranged between controlled and uncontrolled groups in present study and were statistically significant.

\section{DISCUSSION}

A total of 100 subjects were included in the present study out of which 60 were males and 40 females. The mean age of the male and female patients was $50.08 \pm 0.86$ and $51 \pm 1.20$ years respectively. The age difference was not significant between the genders. FBS, PPBS, HbA1c,total cholesterol, triglycerides and LDL were more in females than male patients but the mean values were not significant statistically (Table 1). Only FBS and total cholesterol were statistically significant $(p<0.05)$.

This observation can be compared with a similar study conducted by Wexler et al who reported that the lipid parameters were significantly higher in females as compared to males and were statistically significant. ${ }^{14}$ Eltigani et al did a similar study where in there was a statistically significant association between triglycerides and HDL cholesterol with glucose levels which was more in females than males. ${ }^{15}$ Agarwal $\mathrm{M}$ et al showed that the lipid abnormalities were more among diabetic males than diabetic females which is contrary to our study. ${ }^{16}$ The lipid parameters were deranged between controlled and uncontrolled groups in present study and were statistically significant (Table 2). Amer W et al was a similar study where in all the lipid fractions were deranged in uncontrolled type 2 DM patients which is comparable with present study. ${ }^{17}$

Diabetes mellitus is a common secondary cause of hyperlipidaemia, particularly, if glycaemic control is poor which is an important risk factor for atherosclerosis and coronary heart disease. ${ }^{18}$ There is two to four times increased risk of coronary artery disease among diabetics compared to non diabetic patients. ${ }^{19,20}$ The increased risk of vascular disease in diabetics is in part due to the lipid abnormalities. ${ }^{21}$ Many studies have shown altered lipid profile in diabetes mellitus and dyslipidaemia predisposes to cardiovascular complications specially coronary heart disease among diabetic patients. ${ }^{22-25}$ Hence, we did this study to know the lipid levels among diabetics and compared the lipid levels among controlled and uncontrolled diabetic subjects.

Present study included 100 subjects which is good enough to compare the lipid levels and conclude the co-relation between the glucose levels and lipid profiles among controlled and uncontrolled diabetic population. However, this result cannot be generalised among other diabetic population as this study was done only in a single private medical tertiary care centre, so similar studies are to be done among huge diabetic population to conclude the results.

\section{CONCLUSION}

Present study shows elevated blood glucose levels and lipid parameters among uncontrolled diabetic patients compared to controlled diabetic patients depicting strongly the co relation between the glycemic levels and lipid abnormalities. Patients should be educated about lifestyle modifications and healthy diet, to exercise regularly, to avoid sedentary habits, proper medications, regular monitoring of lipid profiles and follow up with the physician controlling blood sugars and lipids very effectively to reduce the risk of coronary artery disease.

\section{ACKNOWLEDGEMENTS}

Authors would like to thank Mr. Vedamurthy B. J., final year medical student, who helped them in collecting the data for this study.

\section{Funding: No funding sources}

Conflict of interest: None declared

Ethical approval: The study was approved by the Institutional Ethics Committee

\section{REFERENCES}

1. World Health Organization. Definition, diagnosis and classification of diabetes mellitus and its complications. Part 1: diagnosis and classification of diabetes mellitus. Geneva: WHO; 1999.

2. Berry C, Tardif JC, Bourassa MG. Coronary heart disease in patients with diabetes: part I: recent advances in prevention and noninvasive management. J Am Coll Cardiol. 2007;49:631-42.

3. King H, Aubert RE, Herman WH. Global burden of diabetes, 1995-2025: prevalence, numerical estimates, and projections. Dia Care. 1998;21(9):1414-31.

4. Fall CHD. Non-industrialised countries and affluence relationship with type 2 diabetes. $\mathrm{Br}$ Med Bull. 2001;60:33-50.

5. Gupta V, Suri P. Diabetes in elderly patients. JK Pract. 2002;91(4):258-9.

6. Windler E. What is the consequence of an abnormal lipid profile in patients with type 2 diabetes or the metabolic syndrome? Atheroscler Suppl. 2005;6:114.

7. Basit A, Hydrie MZI, Hakeem R, Ahmedani MY, Masood Q. Frequency of chronic complications of type II Diabetes. J Coll Physic Surg Pak. 2004;14:7983.

8. Toto RD. Heart disease in diabetic patients. Semin Nephrol. 2005;25:372-8.

9. Miller M. The epidemiology of triglyceride as a coronary artery disease risk factor. Clin Cardiol. 1999;22(6):S111-6. 
10. The American Diabetes Association. Management of dyslipidemia in adults with diabetes. Dia Care. 1999;22(1):S56-9.

11. Khan HA, Clinical significance of $\mathrm{HbA} 1 \mathrm{C}$ as a marker of circulating lipids in male and female type2 diabetic patients. Acta Diabetol. 2007;44:193-200.

12. Selvin E, Marinopoulos S, Berkenblit G, Rami T, Brancati FL, Powe NR, et al. Meta-analysis: glycosylated hemoglobin and cardiovascular disease in diabetes mellitus. Ann Intern Med. 2004;141(6):42131 .

13. Krentz AJ. Lipoprotein abnormalities and their consequences for patients with type 2 diabetes. Diabetes Obes Metab. 2003;5(1):S19-27.

14. Wexler DJ, Grant RW, Meigs JB, Nathan DM, Cagliero E. Sex disparities in treatment of cardiac risk factors in patients with type 2 diabetes. Dia Care. 2005;28:514-20.

15. Eltigani MA, Barri AM, Bakhel K, Ibrahim M, Abbas A, Mudri M. Lipid profile abnormalities as predictive factor for electrocardiogram changes and coronary artery disease among Sudanese people in Shendi locality. Int Invent J Biochem. 2015;3:1-4.

16. Agarwal M, Patel JP, Lala MK. Association between glycemic control and serum lipid profile in known diabetic patients of civil hospital, Ahmedabad. Int $\mathbf{J}$ Med Sci Public Health. 2016;5:356-60.

17. Amer W, Zafar S, Majrooh A. Comparison of dyslipidemias in controlled and uncontrolled type 2 diabetics. Ann King Edward Med Coll. 2004;10:15860 .

18. Naheed T, Khan A, Masood G. Dyslipidaemias in Type 2 Diabetes Mellitus Patients in a Teaching Hospital of Lahore, Pakistan. Pak J Med Sci. 2003;19(4):283-6.
19. Pyorala K, Laakso S, Uusitupa M. Diabetes and atherosclerosis: an epidemiologic view. Dia Metab Rev. 1987;3(2):463-524.

20. Haffner SM, Lehto S, Ronnemaa T, Pyorala K, Laakso M. Mortality from coronary heart disease in subjects with type 2 diabetes and in nondiabetic subjects with and without prior myocardial infarction. N Engl J Med. 1998;339:229-34.

21. ndirakumari N, Vinutha S, Kambhar C. Study of lipid profile in diabetes mellitus patients who were on glibenclamide and glimeperide. IOSR J Dent Med Sci. 2015;14(1):13-22.

22. Nakhjavani M, Esteghamati AR, Heshmat FE. Dyslipidemia in type 2 diabetes mellitus: more atherogenic lipid profile in women. Acta Medica Iranica. 2006;44(2):111-8.

23. Barrett-Connor E, Giardina EG, Gitt AK, Gudat U, Steinberg HO, Tschoepe D. Woman and heart disease: The role of diabetes and hyperglycaemia. Arch Intern Med. 2004;164(9):9344-942.

24. Lee WL, Cheung AM, Cape D, Zinman B. Impact of diabetes on coronary artery disease in women and men: A meta analysis of prospective studies. Dia Care. 2000;23(7):962-8.

25. Kanaya A, Grady D. Barret-Connor E. Explaining the sex difference in coronary heart disease and mortality among patients with type- 2 Diabetes mellitus; A metaanalysis. Arch Interm Med. 2002;162(15):173745.

Cite this article as: Gangadhar M, Muthahanumaiah NK. Lipid profile among controlled and uncontrolled type-2 diabetic patients in a rural tertiary care center: a comparative study. Int J Basic Clin Pharmacol 2020;9:562-5. 